\title{
LA TESIS DE LA ÚNICA RESPUESTA CORRECTA EN RONALD DWORKIN
}

\author{
RONALD DWORKIN'S ONE RIGHT ANSWER THESIS
}

Giorgio Ridolfi

Università di Pisa

Fecha de recepción: $19-3-20$

Fecha de aceptación: 13-5-20

Resumen: El período tal vez más fecundo en la producción científica de Ronald Dworkin es el que abarca sus dos primeras obras importantes, Los derechos en serio y El imperio de la justicia. En ellas el jurista norteamericano se mueve hacia varios objetivos, a veces incluso contradictorios, y elabora una de sus teorías más características, la de la única respuesta correcta. El ensayo intenta esbozar una lectura unitaria de estos escritos, basándose en los rasgos fundamentales del realismo jurídico y de algunas versiones del positivismo, aunque eso implique pasar por alto muchas de sus partes. Por último, se confronta esta interpretación con el asunto de la tolerabilidad, como mucho teorética, del Derecho injusto, que ella parece admitir.

Abstract: The most fruitful period in Ronald Dworkin's scientific production includes his two first important works, Taking Rights Seriously and Law's Empire. Therein, he pursues various objectives, sometimes even contradictory, and elaborates one of his most caracteristic theories: the one right answer thesis. This essay tries to develop a uniform reading of the cited writings in the light of the fundamental features of legal realism and of some versions of positivism; although this implies overlooking several places in them. Finally, the question is posed wheter this interpretation implies, as it seems, at least theoretical tolerance for evil law.

Palabras clave: principios, sociedad, interpretación jurídica, Derecho injusto Key words: $\quad$ principles, society, legal interpretation, evil law 


\section{REFLEXIONES PRELIMINARES}

Los análisis de filosofía del Derecho, que Ronald Dworkin elabora en Los derechos en serio ${ }^{1}$ y El imperio de la justicia ${ }^{2}$, podrían ser acusadas de superficialidad y de falta de unidad. Además podrían juzgarse demasiado desordenadas para ser examinadas con bastante precisión.

Sin duda, la acusación de falta de unidad comprende una característica fundamental de la obra del jurista norteamericano. Los derechos en serio, tal y como otros escritos suyos, es una antología de ensayos ya publicados y reimprimidos con pocas modificaciones; y el autor no se preocupa adecuadamente de que el conjunto deje ver un plan teórico unitario de base. Por lo tanto, él yuxtapone algunos ensayos que atañen al análisis filosófico del Derecho a otros, menos numerosos, que se ocupan esencialmente de política del Derecho y que, en algunas partes, parecen contradecir lo asumido anteriormente. También El imperio de la justicia, que es en cambio una obra sistemática y totalmente original, aclara suficientemente solo una parte de los problemas que pone de relieve; pero alimenta al tiempo ulteriores perplejidades interpretativas con respecto a los escritos precedentes.

Menos pertinente, en cambio, parece la primera de las acusaciones, la de superficialidad. Solo por las deficiencias expuestas, en efecto, ningún erudito de filosofía del Derecho estaría legitimado para negar importancia a algunas fecundas intuiciones de Dworkin. Esto sería como si a un germanista se le ocurriese negar la grandeza de Franz Kafka, alegando simplemente la fragmentación de sus novelas o sus dificultades para alcanzar una versión definitiva de ellas. Por otra parte, al mismo Dworkin no se le escapó el alcance de sus lagunas teóricas, toda vez que en sus obras se encuentra la ambición de desarrollar un discurso que reuna las vertientes éticas, políticas y jurídicas de su pensamiento. En este sentido, su último escrito sistemático Justicia para erizos ${ }^{3}$ se compromete a delinear un auténtico holismo metodológico,

1 R. DWORKIN, Taking Rights Seriously, Harvard University Press, Cambridge (Mass.), 1977, 2a ed., Duckworth, London, 1978; en castellano, Los derechos en serio, trad. de M. Guastavino, Ariel, Barcelona, 1984.

2 R. DWORKIN, Law's Empire, Harvard University Press, Cambridge (Mass.), 1986; en castellano, El imperio de la justicia: de la teoría general del derecho, de las decisiones e interpretaciones de los jueces y de la integridad política y legal como clave de la teoría y práctica, trad. de C. Ferrari, Gedisa, Barcelona, 1988.

3 R. DWORKIN, Justice for Hedgehogs, Harvard University Press, Cambridge (Mass.), 2011; en castellano, Justicia para erizos, trad. de H. Pons, Fondo de Cultura Económica, Ciudad de México, 2016.

DERECHOS Y LIBERTADES

ISSN: 1133-0937

Número 44, Época II, enero 2021, pp. 137-166

DOI: https://doi.org/10.20318/dyl.2021.5852 
sobre todo al interpretar el Derecho como una rama de la moral; y el siguiente Religión sin dios ${ }^{4}$ brinda una consideración "metafísica" de la unidad del pensamiento a partir de la posición de los seres humanos en el cosmos, de su especificidad y de su limitación gnoseológica.

Dicho esto, cabe señalar que lo siguiente no quiere llegar a ser una precisa reconstrucción de la filosofía jurídica de Dworkin. Esto porque tanto sus primeras obras como las más recientes conllevan, en nuestra opinión, un movimiento de base teóricamente inaceptable. Se trata de un movimiento de sentido iusnaturalista, que en resumidas cuentas acaba por volver la entera estructura filosóficamente discutible y poco original. Por lo tanto, lo mejor que se puede hacer con las páginas de Dworkin es seguirlas cuando desarrollan un discurso que nos parece consistente y original, pero limitarlas, integrarlas o incluso ignorarlas, cuando el discurso se vuelve borroso o contradictorio. En este sentido, se intentará valorizar plenamente los avances más interesantes, y con eso demostrar que siguen siendo válidos también cuando se juzguen inadecuadas otras intenciones teóricas y políticas de su autor.

Pero esos avances ya se encuentran en Los derechos en serio y El imperio de la justicia, y esta es la razón por la que nos ocuparemos principalmente de estas obras. Más bien, no cabe duda que en escritos posteriores, como Justicia con tog $a^{5}$, el propio Dworkin acaba por trivializar sus doctrinas en algunos aspectos. Por lo demás, no consideramos del todo exitosos los intentos holístas de sus obras más recientes, aunque estas muestren rasgos de indudable interés. En Justicia para erizos, por ejemplo, la transición de la crítica al escepticismo interno y externo, que es la parte más válida del libro, a la afirmación de particulares valores éticos, políticos y jurídicos se cumple solo a través de consideraciones sin fuerza teórica. A veces nos atreveríamos a definirlas consideraciones románticas, emocionales. De toda manera, le falta al capítulo IX ${ }^{6}$, en que se discuten estos asuntos, el rigor lógico y argumentativo de otros capítulos, así que el proyecto holístico parece encontrar como mucho algunas pausas ${ }^{7}$.

4 R. DWORKIN, Religion without God, Harvard University Press, Cambridge (Mass.), 2013; en castellano, Religión sin dios, trad. de V. Altamirano, Fondo de Cultura Económica, Ciudad de México, 2014.

$5 \quad$ R. DWORKIN, Justice in Robes, Harvard University Press, Cambridge (Mass.), 2006; en castellano, Justicia con toga, trad. de M. Iglesias Vila y I. Ortiz de Urbina Gimeno, Marcial Pons, Madrid, 2007.

6 Cfr. R. DWORKIN, Justicia para erizos, cit., pp. 239-271.

7 Sobre esto véase también C. LARMORE, "The holes in holism", European Journal of Poltical Theory, 12, núm. 2, 2013, pp. 205-216. 
Por supuesto, esto no excluye que distintas lecturas de la obra dworkiniana sean posibles. Y entre ellas la holísta tiene un lugar particular, porque es al final la favorita del mismo Dworkin. Pero la del holismo metodológico es una lectura tanto interesante cuanto problemática, tal vez demasiado pretenciosa, y deja margen por lo tanto a lecturas adicionales, aunque más selectivas. Y es precisamente a través de una lectura selectiva que, como Dworkin quiere hacer con los derechos, intentaremos tomar realmente en serio su doctrina, incluso su controvertida teoría de la única respuesta correcta ${ }^{8}$.

\section{UN POSITIVISMO SUI GENERIS}

Según las intenciones de nuestro ensayo, la mayor crítica que se le puede hacer a Ronald Dworkin es la de ser en última instancia un partidario del Derecho natural. Mejor dicho, él parece limitarse en definitiva a proclamar algunos valores morales superiores que deben respetarse y llevarse a cabo en el Derecho, sin explicar de manera exhaustiva porqué tenemos que respetarlos y llevarlos a cabo. El motivo es obviamente que, como la mayoría de los partidarios radicales del Derecho natural, él piensa que la superioridad de estos valores puede ser indiscutible, y entonces debe parecer indiscutible,

8 Para delinear el abanico de cuestiones que la obra de Dworkin deja surgir no se puede dejar de remitir a M. COHEN (ed.), Ronald Dworkin and Contemporary Jurisprudence, Rowman \& Allanheld, Totowa (NJ), 1983, que contiene entre los otros ensayos de Jules Coleman, Joseph Raz, Neil MacCormick, H.L.A. Hart y Michael Sandel (además de una respuesta de Dworkin a sus críticos). Utilísima introducción a la obra de Dworkin, sobre todo en el sentido en que intentaremos leerla, son tres ensayos publicados en el volumen de junio 1980 (X, núm. 1) de la revista italiana Materiali per una storia della cultura giuridica: las dos conferencias de Genaro Ruben CARRIÓ, "Le opinioni del prof. Dworkin sul positivismo giuridico" (pp. 143-182; orig. "Prof. Dworkin's Views on Legal Positivism", Indiana Law Journal, LV, núm. 209, 1979), que ponen de relieve las relaciones estrictas y algunos conflictos entre las doctrinas de Dworkin y de Hart; S. BARTOLE, “In margine a 'Taking Rights Seriously' di Dworkin" (pp. 185-208), que analiza las páginas de Dworkin en la perspectiva del constitucionalismo y también esboza una confrontación con la doctrina de la "constitución material" de Costantino Mortati; y G. RUBUFFA, "Costituzionalismo e giusnaturalismo: Ronald Dworkin e la riformulazione del diritto naturale" (pp. 209-229), en que, tomando en consideración las intenciones políticas de Dworkin, se ponen de relieve sus mayores contradicciones teóricas. Véanse también el "Ensayo sobre Dworkin", que Albert CALSAMIGLIA escribió como introducción de R. DWORKIN, Los derechos en serio (cit., pp. 7-29); y del mismo autor "El concepto de integridad de Dworkin", Doxa. Cuadernos de Filosofía del Derecho, núm. 12, 1992, pp. 155-176, basado en cambio en la lectura de El imperio de la justicia.

DERECHOS Y LIBERTADES

Número 44, Época II, enero 2021, pp. 137-166
ISSN: 1133-0937

DOI: https://doi.org/10.20318/dyl.2021.5852 
para todo el mundo. Es una posición que pese a sus esfuerzos teóricos ni siquera cambia de manera sustancial en Justicia para erizos.

Con eso, cabe notar, no se quiere repetir la objeción de muchos críticos de que ya sería Derecho natural la simple apelación dworkiniana a los principios. Solo queremos subrayar que por ciertas razones personales y contingentes Dworkin incluye su doctrina de los principios en una perspectiva de Derecho natural, aunque no esté teóricamente obligado a hacerlo ${ }^{9}$. De ahí que sea posible construir una versión alternativa, más consistente de esta filosofía; una versión que se acerca más al realismo jurídico, y en parte al positivismo, dejando de lado cualquiera relación con el Derecho natural. Sin duda, como ya hemos asumido, no es la versión que Dworkin quiso dar a sus concepciones; pero es asimismo verdad que en sus páginas se puede encontrar casi todo y lo contrario de todo ${ }^{10}$.

El mayor mérito de los análisis de filosofía del Derecho de Dworkin reside, en nuestra opinión, en el hecho de que él deja aparecer toda la fragmentación y la complejidad de la experiencia jurídica. Ella se manifiesta sobre todo en el momento de la declaración del Derecho vigente por los tribunales. Enfrentándose con Hart, Dworkin busca un punto de equilibrio más profundo entre tres vertientes, igual de importantes. Primero, el Derecho pronunciado por los órganos que tienen el poder en una determinada sociedad; es decir, el Derecho que, al menos formalmente, sigue siendo válido hasta que no intervenga un procedimiento de abrogación, implícita o explícita. Segundo, el entorno material de tradiciones y prácticas jurídicas en el que el Derecho surgió en el pasado y sigue surgiendo. Y finalmente la vida que el Derecho cobra cuando entra en contacto con la estructura contingente y los procesos evolutivos de la sociedad sobre la que interviene (a saber, los procesos morales, culturales, económicos, etc.).

9 Parece abordar este tema Baldassare PASTORE, en su ensayo muy puntual I princìpi ritrovati. Saggio su Ronald Dworkin, I.L.A. Palma, Palermo, 1985, p. 34. En lo sucesivo (véanse sobre todo las conclusiones, en las páginas 68-74), él afirma que sería preciso leer Los derechos en serio por encima de la distinción entre positivismo y Derecho natural. Concordamos, como aclarará lo que sigue; pero a condición de que se comprenda que, sean cuales fueren sus intenciones, eso no puede inferirse de manera lineal de las palabras de Dworkin.

10 En este sentido, proporciona una posible, más articulada lectura en clave iusnaturalista de la entera obra de Dworkin, M. LALATTA COSTERBOSA, "Ronald Dworkin e il diritto naturale come integrità", en Il diritto come ragionamento morale. Saggio sul giusnaturalismo contemporaneo e le sue applicazioni bioetiche, Rubbettino, Soveria Mannelli, 2007, pp. 109-142. 
La dinámica jurídica que Dworkin describe exige que cada decisión judicial, al menos por principio, pueda ser rastreada hasta una afirmación anterior de autoridades legislativas o constituyentes. Esas autoridades identifican así explícitamente la disciplina que debe aplicarse en casos determinados o, como mínimo, indican que en algunos casos deben aplicarse las costumbres sociales o jurídicas vigentes. Por supuesto, y ya no solamente en los ordenamientos de common law, entre las autoridades legislativas se hallan los mismos tribunales. De hecho, sus precedentes son un espejo de la cultura jurídica de un Estado, sobre todo en lo que atañe a la interpretación del Derecho escrito; y son también el lugar privilegiado donde se reconoce la vigencia positiva del Derecho no escrito.

Entonces, los legisladores y otras autoridades legislativas similares pueden emitir estipulaciones contingentes, si bien generalmente ni irrazonables ni irracionales. Pero las actividades de los tribunales no pueden desarrollarse en manera arbitraria, sino tienen que buscar un fundamento en hechos jurídicos preexistentes; o bien en el balance de ellos, cuando los hechos normativos y los dados jurídicos sociales se contradigan ${ }^{11}$.

A pesar de esto, Dworkin no piensa que la solución de las controversias tiene que deducirse lógicamente del material jurídico disponible, según la visión utópica de Montesquieu: el juez es la boca que pronuncia las palabras de la ley. Al contrario, en su opinión, dichas soluciones pueden ser solamente construcciones argumentativas realizadas a partir de este material. Esto porque, como demuestran los llamados casos difíciles (hard cases), el Derecho positivo deja fuera de sí innumerables asuntos, que prima facie no pueden encontrar una solución. Y también porque algunos documentos jurídicos, sobre todo las constituciones, no enuncian reglas, sino principios que pueden ser derogados y están sujetos a recíproca ponderación. Y finalmente porque el Derecho positivo, según Dworkin, no puede depender de la intención de sus redactores. Ella es también difícil de reconstruir, y se trasforma en consonancia con las inevitables transformaciones de la sociedad ${ }^{12}$. Este punto

11 En este sentido, aunque de una manera no suficientemente detallada, se mueve K. GREENAWALT, "Policy, Rights, and Judicial Decision”, en M. COHEN (ed.), Ronald Dworkin and Contemporary Jurisprudence, cit., pp. 109-112, que llega a conclusiones no diferentes de nuestras.

12 En el subpárrafo de El imperio de la justicia titulado “¿Quiénes son los autores de un estatuto?", Dworkin plantea una eficaz serie de preguntas sobre una ley particular de los Estados Unidos -el Endangered Species Act-, que sin embargo podrían aplicarse a todas las leyes": «¿Los estados mentales de qué personas cuentan al fijar la intención detrás [de la ley]? 
de vista, por lo tanto, "rechaza, por inútil, la antigua cuestión si los jueces encuentran o inventan la ley; sugiere que entendemos el razonamiento legal solo al entender el sentido en el que hacen ambas cosas y ninguna" ${ }^{13}$.

En resumen, para Dworkin la cuestión del ¿quid iuris?, tal y como la del ¿quid ius?, solo puede ser una cuestión interpretativa. Esto significa que todo el Derecho concreto, tal y como se estructura a partir de la actuación de los jueces, es un resultado de la interpretación; aunque el de la interpretación nunca sea un proceso arbitrario, sino que parte de textos, de actos y de estables comportamientos jurídicos existentes de antemano.

Es verdad que los jueces también pertenecen a la sociedad en que viven, compartiendo generalmente sus valores. Pero esto no implica que ellos puedan forzar el material jurídico que tienen a su disposición, cuando ninguna interpretación de sentido común parezca adecuada a la afirmación de los valores sociales difusos. La interpretación se convertiría en arbitraria creación de Derecho, si los intérpretes pretendiesen incumplir la fidelidad al material jurídico positivamente dictaminado o transmitido. Ellos tienen siempre que aguardar la conclusión de un procedimiento de abrogación, explícita o implícita (en sentido amplio); y no pueden leer sus partes más controversas basándose en principios morales individuales o característicos solo de grupos minoritarios.

Esta manera de leer la obra de Dworkin tiene el mérito, en nuestra opinión, de esbozar una forma ampliada, y por lo tanto sui generis, de positivis$\mathrm{mo}^{14}$. En ella, junto a los valores positivamente declarados en el ordenamiento, se halla la ética política desarrollándose y imponiéndose en la sociedad, con miras a la delimitación, pero nunca a la aniquilación, del carácter vincu-

¿Cada uno de los miembros del Congreso que la sancionó, incluyendo aquellos que votaron en contra? ¿Las ideas de alguno, por ejemplo, las de aquellos que hablaron o hablaban más a menudo en los debates, son más importantes que las de otros? ¿Qué sucede con los funcionarios ejecutivos y asistentes que prepararon los borradores iniciales? ¿Qué pasa con el presidente que firmó el proyecto de ley y lo hizo ley? ¿Sus intenciones no deben contar más que las de cualquier senador? ¿Qué hay de los ciudadanos particulares que escribieron cartas a sus congresistas o que prometieron o amenazaron con votar a favor o en contra de ellos, o con hacer contribuciones para las campañas, dependiendo de la forma en que ellos votaran? ¿Y qué sucede con las camarillas o los grupos de acción que jugaron el rol que ahora se considera normal?"»(R. DWORKIN, El imperio de la justicia, cit., p. 226).

13 Ivi, p. 164.

14 De positivismo sui generis habla B. PASTORE, I principi ritrovati, cit., p. 72, respondiendo a A. PINTORE, Norme e principi. Una critica a Dworkin, Giuffrè, Milano, 1982, pp. 69-71, que habla en cambio de Derecho natural sui generis. 
lante del Derecho vigente y al rechazo al mismo tiempo de cada principio metafísico.

Entonces, se puede hablar para Dworkin de un positivismo incluyente. Sin duda, los documentos a los que se da mayor importancia en su doctrina son los que enuncian y dictaminan los valores vinculantes del ordenamiento, como en el caso de las constituciones. Pero se debe hablar al mismo tiempo y principalmente de un positivismo excluyente. En su opinión, como para Joseph $\operatorname{Raz}^{15}$, un valor parece justificarse en un ordenamiento solo como resultado de la argumentación jurídica adecuadamente motivada de legisladores, funcionarios y jueces, es decir de sus autoridades reconocidas. En este modo, pierde toda su naturaleza ética original; y nada puede significar que no exista un pedigree test establecido para determinar qué principios morales pueden volverse en jurídicos y en qué condiciones ${ }^{16}$.

Pese a esto, tenemos que seguir hablando de positivismo sui generis porque, como ya se ha subrayado, estamos frente a una forma de positivismo mezclada con algunos rasgos fundamentales del realismo jurídico: en primer lugar, la apremiante atención a los datos empíricos de la vida social.

\section{3. ¿PRESCRIPCIÓN O DESCRIPCIÓN?}

Una interpretación semejante, cabe asimismo añadir, no puede referirse solamente a ordenamientos democráticos, tampoco en el sentido igualitario

15 Cfr. J. RAZ, Practical Reason and Norms, Hutchinson, London, 1975 (2a ed., Oxford University Press, Oxford, 1999); en castellano, Razón práctica y normas, Centro de Estudios Constitucionales, Madrid, 1991.

16 De estas connotaciones positivistas de la obra de Dworkin parece darse cuenta E. Philip SOPER en "Legal Theory and the Obligation of a Judge: The Hart/Dworkin Dispute", en M. COHEN (ed.), Ronald Dworkin and Contemporary Jurisprudence, cit., pp. 3-27 (especialmente 16-20). No obstante, él intenta llevar la rights thesis a una cierta concordancia con el pedigree test de la norma de reconocimiento de Hart. En su "Reply" contenido en el mismo libro, DWORKIN critica a Soper por tomar posiciones en cierto sentido metafísicas con respecto a la relación entre Derecho y moral. Pero, para lo que atañe a la posible concordancia de sus posiciones con el positivismo, Dworkin afirma que no le interesa "discutir con Soper sobre las denominaciones. Argumenté que el positivismo hace [...] afirmaciones que en cambio su versión no hace, y mi disputa es con estas afirmaciones, no con etiquetas" (ivi, p. 247). Sin embargo, se puede también tener presente lo que Aldo SCHIAVELLO repite varias veces en Diritto come integrità: incubo o nobile sogno? Saggio su Ronald Dwokin, Giappichelli, Torino, 1998: Dworkin acaba por crear una versión ficticia e incompleta del positivismo, para destrozarla más fácilmente.

DERECHOS Y LIBERTADES

ISSN: 1133-0937

Número 44, Época II, enero 2021, pp. 137-166

DOI: https://doi.org/10.20318/dyl.2021.5852 
que hoy en día tiene la palabra "democracia". En efecto, imaginemos un hipotético Estado en el cual la mayoría blanca afirme casi unánimemente que la minoría negra no pertenece al género humano y, pese a esto, administre los demás asuntos políticos conforme a los más puros principios de la democracia liberal. Por supuesto, semejante hipocresía nos horrorizaría. Pero ¿cómo se puede sostener que en este Estado no existen principios? Y ¿cómo se puede sostener que no es el mismo principio de discriminación uno de los principios fundamentales del Estado? Más bien, la misma democracia debe interpretarse como uno de los posibles principios fundamentales de un ordenamiento, tanto en sentido igualitario como en sentido mayoritario ${ }^{17}$. Entonces ser democráticos no es algo que pueda servir para establecer diferencias entre los que pueden ser llamados ordenamientos y los que no pueden. Por eso, no habría diferencias en este sentido entre Estados democráticos y Estados que rechazan explícitamente la democracia.

Como demuestra el caso del régimen nazi, es posible que una oligarquía aproveche la desidia y el miedo de muchos ciudadanos y infunda su ideología criminal en la mayoría del pueblo, determinando en manera sustancial sus ideas sobre el Derecho y la política. Pero también esta aclaración tiene un sentido relativo. De hecho, podríamos hacer un discurso semejante para una oligarquía que a través de una política terrorista consiguiera sistemáticamente doblegar o incluso aniquilar a la voluntad (teóricamente) reacia de la gran mayoría. Por eso, cuando hablamos de valores sociales difusos, no tenemos siempre que referirnos a los valores reconocidos por cada miembro de la sociedad. Nos referimos en cambio a los valores generalmente reconocidos por los miembros que en esta sociedad tienen voz y voto, aunque puedan ser una pequeña minoría. En el mismo sentido, cuando hablamos de jueces, no podemos pensar solamente en la división de los poderes típica de las modernas sociedades políticas. Podemos también imaginar casos en que otros poderes, en particular el ejecutivo, incorporen, invadan o influyan gravemente en el poder judicial.

Aclarado esto, es menester repetir que este no es el sentido que Dworkin quiso dar a sus investigaciones. En efecto, su obra quiere ser una justificación de la actuación de los tribunales norteamericanos, y sobre todo del Tribunal

17 Dworkin expresa una visión claramente igualitaria de la democracia, como puede verse en algunos ensayos suyos más centrados en la cuestión de los derechos. Sobre esto, F.J. ANSUATEGUI ROIG, Razón y voluntad en el Estado de Derecho.Un enfoque filosófico-jurídico, Dykinson, Madrid, 2013, pp. 333-335. 
Supremo de los Estados Unidos. Esto porque, a partir de los años 50, estos tribunales empezaron a desarrollar una jurisprudencia contraria a la segregación racial y favorable a los derechos humanos y civiles. En este asunto Dworkin se enfrenta con los partidarios del originalismo constitucional, ciegos a la cuestión de la correspondencia entre la legislación positiva y las transformaciones de la ética social; y expresa una concepción evolutiva del Derecho que quiere justificar un punto de equilibrio progresista.

Pero, a Dworkin es posible fácilmente objetarle que no toma suficientemente en consideración la posibilidad contraria, es decir la posibilidad de que su concepción pueda ser del mismo modo utilizada, también en los Estados Unidos, para justificar una jurisprudencia regresiva ${ }^{18}$. Para evitarlo, él introduce en la búsqueda del Derecho vigente la referencia a un principio de "igual respeto y consideración" para todo los sujetos del ordenamiento, describiendolo explícitamente "como fundamental y axiomático" ${ }^{19}$. En un sentido que podríamos definir radbruchiano, él parece utilizar este principio para distinguir, al menos hoy en día, lo que es Derecho de lo que es demasiado injusto para serlo ${ }^{20}$. En la perspectiva dworkiniana, este principio tal vez

18 Concordamos con Alfonso GARCÍA FIGUEROA, cuando, al subrayar las contradicciones evidentes en la teoría de Dworkin, sostiene que el autor norteamericano "parece más interesado en persuadir a sus interlocutores, que en describir la realidad. Esta dimensión rétorica constituye un indicio fundamental de su dimensión ideológica, política. La ambigüedad de Dworkin en el plano metaético y las contradicciones derivadas de su "actitud antianalítica" parecen obedecer a un objetivo superior de carácter ideológico: la defensa del Estado de derecho, en cuanto protector de ciertos derechos individuales frente a los cálculos utilitaristas del Estado" (Principios y positivismo jurídico. El no positivismo principialista en las teorías de Ronald Dworkin y Robert Alexy, Centro de estudios políticos y constitucionales, Madrid, 1998, pp. 295-296). Por lo demás, García Figueroa reconoce la dificultad de incluir a Dworkin en el iusnaturalismo o bien en el positivismo jurídico. Solo ofrece en nuesta opinión una interpreción demasiado estricta y literal de la doctrina de la única respuesta correcta.

19 R. DWORKIN, Los derechos en serio, cit., p. 41.

20 Se cite enteramente la frase: “El libro sugiere [...] una forma preferida de defensa de los derechos políticos, que es la derivación de derechos particulares a partir del derecho abstracto a igual consideración y respeto, que se toma como fundamental y axiomático. [...] [E]l derecho a igual consideración y respeto es fundamental [...], porque [...] es posible derivar de ese derecho [...] la idea misma de una meta colectiva. Si es así, entonces la igualdad de consideración y respeto configura un derecho tan fundamental que no cabe dentro de la caracterización general de los derechos como valores superiores las metas colectivas, excepto como caso límite, porque es tanto la fuente de la autoridad general de los fines colectivos, como de las limitaciones especiales a tal autoridad que se justifican en virtud de derechos más particulares»" (ibidem). El paso final en este camino, como ya se ha dicho en el texto, Dworkin lo cumple en Justicia para erizos.

DERECHOS Y LIBERTADES

ISSN: 1133-0937

Número 44, Época II, enero 2021, pp. 137-166

DOI: https://doi.org/10.20318/dyl.2021.5852 
es útil también para justificar la actuación innovadora de algunos tribunales. Esto ocurrió, por ejemplo, cuando la ética progresista de sus miembros, aunque abstractamente compatible con las palabras de la Constitución, aún no correspondía a la ética difusa en la Federación.

Las cosas no cambian cuando Dworkin, en El imperio de la justicia, deja de lado esta formulación para introducir lo que llama un principio de integridad hermenéutica del Derecho. También en este caso él acaba por postular la existencia de valores axiomáticos para el justo reparto de los derechos entre los miembros de un ordenamiento.

Es evidente que en ambas obras no se encuentran más que huecas declaraciones de principio. Además, a ellas nunca les corresponde un oportuno análisis teórico para fundamentarlas de manera similar a experiencias cercanas, pero en eso más estructuradas: por ejemplo las de Jürgen Habermas o de la Escuela de Sheffield ${ }^{21}$.

Aquí hay también otros motivos de perplejidad. Refiriéndose al igual respeto y consideración, Dworkin parece pensar en la equal protection clause expresada en la Enmienda XIV de la Constitución de los Estados Unidos. Por lo tanto parece referirse a un público que tiene este documento como horizonte jurídico. Esto significa que Dworkin se refiere a métodos de construcción jurídica que valen solamente para un tipo de experiencia o, como mucho, para ella y las que se le parecen. Es verdad que, en los rasgos fundamentales, al ordenamiento consitucional norteamericano le parecen todos los ordenamientos occidentales modernos. Pero estos están lejos de agotar todos los tipos posibles de experiencia jurídica en el espacio y en el tiempo.

Entonces, una de dos cosas: o Dworkin se ocupa de asuntos importantes, pero que no tienen un valor universal; o su concepción no es suficientemente estructurada desde el punto de vista de la interpretación del Derecho ${ }^{22}$. De todas maneras, cabe notar que sería difícil adecuar un sistema tan complejo a experiencias jurídicas y judiciales bastantes primitivas. Y Dworkin, aunque se refiera en algunas páginas a un impreciso "concepto de derecho de uso

21 Sobre esto véase M. LA TORRE, "Idealismo giuridico. Il neogiusnaturalismo, la Scuola di Sheffield, e la teoria del discorso", en Il diritto contro se stesso. Saggio sul positivismo giuridico e la sua crisi, Leo S. Olschki, Firenze, 2020, pp. 143-170.

22 Aldo Schiavello, que en la obra citada subraya la superficialidad y la falta de unidad y de orden argumentativo en las obras de Dworkin, sostiene en su crítica la primera de esas opciones. Así demuestra como es posible reconstruir convincentemente la doctrina dworkiniana en maneras alternativas. 
general hoy" 23 , no ayuda a los lectores indicando umbral más allá del cuál su análisis ya no es adecuado ${ }^{24}$.

Aún más interesante es preguntarnos, como casi todos los intérpretes de Dworkin, si sus doctrinas tienen un carácter descriptivo o uno prescriptivo; es decir si ellas son una reconstrucción de lo que normalmente hacen los tribunales, o bien un llamamiento a ellos para que se comporten de una determinada manera. Si es verdad que su doctrina con el tiempo se ha vuelto siempre más prescriptiva, el Dworkin de Los derechos en serio parece moverse hacia una posición media en esta alternativa. Esto indica su conciencia de que dar una lectura estrictamente descriptiva de sus tesis significaría ser desmentido por un montón de pruebas de lo contrario; salvo que no se sostenga la opinión absurda de que los jueces, cuando se equivocan, toman sus decisiones creyendo de buena fe que están haciendo lo contrario de lo que hacen. Y esta es precisamente la crítica que Dworkin siempre puso a las pretensiones descriptivas del positivismo de Hart. En qualquier caso, en El imperio de la justicia, él niega expresamente semejante interpretación, poniendo de relieve tres macroconcepciones interpretativas -la convencionalista (positivista), la pragmatista (escéptico-realista) y precisamente la inspirada en el principio de integridad (y entonces de igualdad)- entre las cuales, afirma, los jueces elijen al pronunciar sus sentencias.

Por eso, una posición media implicaría la posibilidad de reconstruir la manera en que los jueces, en un número considerable de casos, eligen actuar; pero también el reconocimiento del hecho de que ellos hacen bien en actuar así y que todos sus colegas tendrían que emularlos. Al afirmarlo, sin embargo, surge de nuevo por la mitad descriptiva la sospecha que Dworkin se refiera solo a experiencias jurídicas particulares; y surge, por la mitad prescriptiva, otra pregunta: ¿en qué sentido se puede afirmar que es mejor decidir los casos en una manera en vez que en otra? ${ }^{25}$ Si descartamos la remisión

23 R. DWORKIN, Los derechos en serio, cit., p. 103.

24 Tampoco parece satisfactorio lo que Dworkin escribe más recientemente: “¿Cuán universal puede ser una teoría interpretativa de la doctrina jurídica? Supongamos que procedemos a construir una interpretación de la práctica jurídica que se ajuste a todo lo que consideramos que cae dentro del concepto sociológico de derecho. ¿Cuánto detalle podría contener esta interpretación tan abstracta? Quizá muy poco: puede suceder que una vez iniciado el proceso cada paso interpretativo que efectuemos haga que nuestra explicación interpretativa se vuelva más parroquial. [...] De este modo la mejor respuesta a la cuestión de si mi teoría del derecho pretende ser universal o parroquial es: ambas cosas" (R. DWORKIN, Justicia con toga, cit., pp. 251-252).

25 De esto se percata Michel TROPER, según el cual “Dworkin exige justificar sus prescripciones con la descripción de lo que hacen ciertos jueces en ciertos casos. En otras palabras, 
a valores axiomáticos, a Dworkin parece quedarle solo esta constatación: en los hechos los jueces balancean, más de lo que se puede creer, el Derecho escrito con el Derecho existente pero no escrito. No obstante, como deja claro la doctrina de la única respuesta correcta, que trataremos más adelante, semejante modus operandi ofrecería a la hazaña de construcción y reconstrucción jurídica una base más sólida desde el punto de vista empírico.

Esto significa que nadie tiene que sostener que el Derecho es mejor que la anarquía. Esta es una cuestión que atañe a las inclinaciones de las personas y al sentido común de una sociedad. Pero, cuando alguien lo sostiene, su concepción puede solo basarse o en abstractos enunciados de principio, sobre los que el acuerdo es muchas veces más aparente que efectivo; o bien en el reconocimiento empírico de la estabilidad que a la experiencia jurídica le proporcionan los concretos movimientos sociales y los enunciados formales (esto es, positivos) que ellos contingentemente producen.

Con mayor razón, no se puede sostener que concepciones del Derecho diferentes de esta son erróneas o que nunca se realizaron. Pero sí que, si las comparamos con una teoría interpretativa, solo esta parece capaz de brindarnos una visión general de todas las vertientes al tiempo abstractas y concretas del fenómeno jurídico.

Seguramente esto no es todo y no es lo que Dworkin quisiera. Pero tal vez no es poco.

\section{DERECHO Y JUEGOS: ESENCIA Y FUNCIÓN DE LOS PRINCIPIOS}

En el capítulo de introducción de Los derechos en serio, Dworkin intenta encontrar una síntesis entre los ensayos más teóricos de la primera parte y los más políticos de la segunda. En este sentido él esboza una posición jurídico-política que llama "teoría de los derechos". Cada conjunto social, dice, se caracteriza por una dialéctica entre las posibles decisiones de la mayoría y los derechos de los individuos. Frente a algunas legítimas pretensiones de algunos individuos, "una meta colectiva no es justificación suficiente para negarles lo que, en cuanto individuos, desean tener o hacer" y "no justifica que se les imponga alguna pérdida o perjuicio" ${ }^{26}$.

él intenta fundamentar un deber-ser en un ser y, además, en un ser incierto" (La théorie du droit, le droit, l'état, Paris, PUF, 2001, p. 44).

26 R. DWORKIN, Los derechos en serio, cit., p. 37. 
Pronto encontramos el primer problema. Como Dworkin parece descartar, no podemos leer los derechos válidos en el libro de la naturaleza, en el de la tradición o en ninguna revelación religiosa. Entonces, ¿dónde podemos leerlos? Tampoco, segun él, es posible una rigurosa deducción lógico-racional, conforme a la cual un derecho para determinarse como tal necesitaría de una puntual demostración de apoyo.

Los derechos viven en la sociedad y en su historia institucional, y se integran en prácticas argumentativas y narrativas características tanto de sus destinatarios como de los funcionarios encargados de su implementación. Entonces, ellos comparten una fundamental e insuprimible dimensión histórica, sin la cual no puede explicarse el rechazo de su lectura metafísica. Pero esta dimensión determina la absoluta relatividad de los derechos y perjudica la posibilidad de incluirlos en superiores declaraciones de principio. No está claro cómo en este sentido puede introducirse el valor axiomático del principio de igualdad de respeto y consideración (y tampoco del principio de integridad, del que se hablará en El imperio de la justicia). Cabe notar que, después de haberlo enunciado en el capítulo introductivo, Dworkin ya no lo menciona en los primeros ensayos que constituyen la obra, donde expresa los pilares de su posición filosófico-jurídica.

Esta primera parte de la obra de 1977 se caracteriza por la distinción entre principios y políticas (principles and policies); es decir entre los valores de moralidad jurídica y política típicos de un determinado ordenamiento y los fines contingentes que sus órganos políticos pueden querer alcanzar. Esta distinción es semejante a la afirmada anteriormente entre las decisiones de la mayoría y los derechos de los individuos contra ella. Esto significa que los principios también salen de una pluralidad de fuentes bastantes heterogéneas.

Es posible, en primer lugar, individuar conceptos generalísimos que se aplican a cada Derecho histórico conocido. Si las palabras no fuesen un poco equívocas, podríamos individuarlos como la esencia ontológica del Derecho. Estos conceptos se refieren, más que a los contenidos, a los esquemas de funcionamiento de todos los fenómenos históricamente, aunque solo básicamente, clasificables como Derecho: los de regla, de sanción, de responsabilidad, etc., más allá de sus diferentes declinaciones prácticas. Y, al caracterizarse como aún más fundamentales de los principios de ética procedimental expuestos por Lon Fuller ${ }^{27}$, se refieren, más en general, a la oposición del

27 Cfr. L. FULLER, The Morality of Law, Yale University Press, New Haven (CT), 1964. 
Derecho a su negación estructural, es decir la anarquía, interpretada en sentido estricto como falta de toda ley.

$\mathrm{Si}$ a estos principios se les quiere proporcionar un marco desde el punto de vista del contenido, muestran una cierta relación con lo que Hart llamó "contenido mínimo de Derecho natural". Con esta fórmula el filósofo inglés se refiere a las estructuras jurídicas arraigadas en los límites de la constitución física y psíquica, además que lingüística, de los seres humanos ${ }^{28}$. Como dice Hart, no son postulados metafísicos, sino estructuras válidas rebus sic stantibus, hasta que intervenga un cambio radical, no previsibile pero abstractamente concebible, de algunas características de la naturaleza humana. Se puede pensar, si queremos un ejemplo, en las transformaciones que podrán manifestarse el día, tal vez no demasiado lejano en el futuro, en que sea posible realizar la hibridación del cuerpo humano con dispositivos electrónicos o informáticos.

Por supuesto, no es posible introducir entre estos conceptos teoréticos generalísimos una remisión a valores morales. Tampoco se puede introducir en ellos la igualdad de respeto y consideración para cada miembro del ordenamiento, que se encuentra solo en un número limitado de ordenamientos y solo en los últimos siglos. Este principio no es más que una de aquellas afirmaciones de moralidad política que en la modernidad han encontrado un lugar peculiar para expresarse en las constituciones y en los documentos con valor constitucional. Por eso nos hallamos frente a conceptos de alcance general, que no obstante poseen una universalidad solamente tendencial; aunque las constituciones que los transmiten se incluyan a menudo en amplios paradigmas supranacionales, como por ejemplo el occidental. Lo cual, sin embargo, no significa que solamente los Estados que poseen una constitución escrita, o que, como en el caso inglés, pueden derivarla de una serie de documentos, tengan un sistema de principios. Los que lo pensaran no comprenderían además la misma esencia del conjunto de los principios constitucionales, que está formado por una serie de afirmaciones bastantes explícitas, pero está muy lejos de agotar toda la ética política de un Estado.

28 Cfr. H.L.A HART, El concepto de Derecho, trad. de G.R. Carrió, Abeledo Perrot, Buenos Aires, 1977, pp. 239-247; orig. The Concept of Law, Oxford University Press, Oxford, 1961; 2a ed. póstuma, Clarendon Press, Oxford, 1994, con el célebre Post Scriptum, en que se desarrolla un confronto con las doctrinas de Dworkin (en castellano, H.L.A HART, Post scríptum al concepto de derecho, trad. de R. Tamayo y Salmorán, Universidad Nacional Autónoma de México, Ciudad de México, 2000). 
En efecto, los principios constitucionales explícitos pueden tanto combinarse en abstracto entre sí para establecer algunos implícitos y a menudo más fundamentales (piénsese al principio de dignidad humana, no expresado claramente en la Constitución italiana, y que no obstante el Tribunal Constitucional ha indicado como el supremo); como pueden estar relacionados con los procesos evolutivos de la legislación y de la ética social. Estos son los principios que ambas expresan, hasta que no se produzcan jerarquías contingentes para proporcionarles a las controversias jurídicas una solución adecuada.

De todas maneras, cabe subrayar que los principios constitucionales no expresan siempre con claridad el sentido de las prácticas políticas que dan forma a un determinado ordenamiento. En los Estados Unidos, por ejempo, estas prácticas pueden reconocerse en los principios del precedente vertical y horizontal (stare decisis), de la democracia y del federalismo ${ }^{29}$. Por último, tenemos que reconocer que " $[\mathrm{t}]$ ambién nuestros principios [...] podrían verse cuestionados, y en tal caso no solo los defendaríamos en función de la práctica aceptada, sino en función de sus relaciones recíprocas y de las implicaciones de tendencias de las decisiones judiciales y legislativas, aun cuando esto último significara apelar a aquellas mismas doctrinas de la interpretación que justificábamos por mediación de los principios que ahora intentamos fundamentar" 30 .

Reintroduciendo una similitud habitual, que Dworkin también utiliza, podemos afirmar que los principios que se refieren a la esencia del Derecho se caracterizan como un concepto abstracto de "reglas del juego". Las reglas de un juego son las estructuras que permiten ver una serie de comportamientos de algunos individuos como "movimientos" o "acciones", y precisamente su conjunto como un juego. Sería difícil seguir hablando de "juego", cuando, por ejemplo, la única regla suya fuera la de la absoluta discrecionalidad del árbitro. En este caso dos situaciones similares pudieran siempre

29 En Justicia con toga DWORKIN enumera las proposiciones fundamentales de la democracia americana: “[P]rimera: la democracia no es sólo la regla de la mayoría, sino una asociación en el autogobierno; segunda: tal asociación se estructura y es hecha posible por una constitución moral que garantiza a todos los individuos los prerrequisitos de la plena membresía; tercera: por nuestra historia, estamos comprometidos con una estrategia institucional que exige a los jueces (hombres y mujeres entrenados en el derecho) que apliquen esas garantías de igualdad ciudadana" (cit., p. 157). Entonces, son un particular documento legislativo, como la Constitución de 1787, y una determinada historia política que determinan contingentemente las decisiones que los jueces americános tienen que tomar y los valores que en ellas tienen que respetar.

30 R. DWORKIN, Los derechos en serio, cit., p. 96. 
encontrar dos diferentes soluciones, no previsibles al basarse en un criterio establecido de antemano.

Los principios constitucionales pueden compararse con proposiciones que ilustran los rasgos y los valores fundamentales de un juego particular, de conformidad con los cuales se pretende que los participantes interpreten dicho juego. Sin embargo, esto no significa que un juego dejaría de serlo en caso de que sus principios fundamentales se modificasen, o bien se leyesen de forma que permitan una evidente desnaturalización de lo que se creía su "núcleo duro". En efecto, nada más que el sentido común prohibe, por ejemplo, que en su próxima reunión el Ifab (International Football Association Board), el órgano encargado de modificar las reglas del fútbol, establezca que, a partir de una determinada fecha, también los porteros puedan utilizar solo los pies, que todos los jugadores puedan utilizar las manos, o incluso que constituya una irregularidad para todos los futbolistas el uso de los pies. De la misma manera, nada más que una moralidad política educada por las tragedias históricas, además de la dificultad de liberarse de algunas obligaciones supranacionales, prohibe al parlamento alemán intentar una modificación del Grundgesetz, o incluso una nueva interpretación de sus principios, que haga posible la reintroducción de las leyes raciales. El fútbol seguiría siendo un juego -aunque un juego muy diferente del original y, probablemente, mucho menos interesante-, también si se empezara a jugar solo con las manos, así como Alemania seguiría siendo un Estado, y su Derecho seguiría siendo Derecho, también si sus políticos optaran por volver a los momentos más oscuros de su historia.

Además, hay en los juegos también reglas menos fundamentales, cuya introducción o cuya modificación demostraría el intento de los reformadores de interpretar de una determinada manera una regla superior. $Y$ hay prácticas de juego, que no están reguladas y, en algunos casos, no pueden regularse. A pesar de esto, ellas se toleran o se consideran lícitas, pero el sentido común de los jugadores o de los árbitros frente a ellas puede transformarse en un determinado período de tiempo. Por eso, debe quedar claro que las constituciones y los textos con valor constitucional no enumeran simplemente una serie de criterios para examinar la conformidad de la legislación de un conjunto social y los comportamientos de sus miembros. Esto tanto porque los principios expresados por las constituciones y los textos con valor constitucional poseen una formulación general que no permite ictu oculi la solución de todos los casos contingentes; como porque a menudo la legislación y la vida de un conjunto social expresan autónomamente principios jurídicos o 
brindan nuevas interpretaciones de los principios ya enunciados, refiriéndose a veces a fines concretos de extrema urgencia.

Cabe asimismo subrayar que, también en los paises de civil law, los precedentes de los tribunales adquieren siempre mayor impacto. Y, cuando se toman en consideración los precedentes, se acaba por crear jerarquías entre los principios. Estas jerarquías permanecen en vigor hasta qua una nueva y detallada construcción argumentativa no sea capaz de demonstrar plenamente su falacia (original o sobrevenida) ${ }^{31}$. Por eso, puede afirmar Dworkin, “[c]uando un juez escoge entre la norma establecida en el precedente y una norma nueva que se considera más justa, no está eligiendo entre la historia y la justicia; más bien, formula un juicio que le exige cierto compromiso entre consideraciones que ordinariamente, en cualquier cálculo de derechos políticos, se combinan, pero que aquí entran en competencia" ${ }^{32}$.

En resumen, el funcionamiento del ordenamiento que Dworkin describe se basa tanto en la centralidad de los principios como en su característica peculiar de ser derogables. Esto significa que los principios están sujetos a un balance que, en algunas decisiones, los deja de lado o desempodera, sin no obstante poner en duda su existencia o vigencia. Cuando se trata de decidir casos no cuestionados, este ordenamiento parece ser un sistema de prescripciones legislativas positivas y precedentes judiciales provistos de una cierta estabilidad. Pero, cuando surgen los llamados hard cases, el sistema puede desarrollar sus decisiones solo al adecuar prescripciones y precedentes insuficientes a través de la acción concertada de los principios existentes; y debe tomar asimismo en consideración los efectos que ellos ensayan cuando en-

31 Escribe DWORKIN en manera esclarecedora a propósito de algunos principios explícitos: "Si dejara de parecer injusto permitir que la gente se beneficie de sus delitos, o ya no se considerase justo imponer responsabilidades especiales a los oligopolios que fabrican máquinas potencialmente peligrosas, estos principios dejarían de desempeñar un papel importante en los casos nuevos, aun cuando jamás hubieran sido derogados o rechazados. (De hecho, poco sentido tiene hablar de que principios como éstos sean "derogados" o "rechazados", ya que cuando se suprimen es porque se desgastan, no porque se los impugne)"(ivi, p. 95).

32 Ivi, p. 154. Por supuesto, existen también diferencias fundamentales entre el Derecho y los juegos. Como afirma DWORKIN, “[a] diferencia de lo que sucede con el ajedrez, en la adjudicación de competencia el argumento en favor de una norma determinada puede ser más importante que el argumento que lleva desde esa norma al caso particular; y así como es probable que el árbitro de ajedrez que decide un caso apelando a una regla de la cual nadie ha oído hablar lo descalifiquen o lo den por loco, en el caso del juez lo más probable es que lo celebren en las clases magistrales de la facultad" (ivi, pp. 184-185). 
tran en contacto con los valores y las necesidades de la vida social actual. Por otra parte, lo que a menudo diferencia los casos fáciles de los difíciles es solamente el grado de evolución cultural de una sociedad, es decir la fluctuación histórica de lo que en ella puede definirse "sentido común".

\section{5. ¿UNA ÚNICA RESPUESTA CORRECTA?}

El cumplimiento de estas concepciones se halla en la doctrina de la única respuesta correcta, que es uno de los rasgos más peculiares y, en cierto sentido, de mayor originalidad en la obra de Dworkin.

Como ya se ha dicho, según él, es posible en abstracto enumerar todos los elementos jurídicos existentes: ideas generales sobre el Derecho, principios constitucionales, leyes positivas, precendentes judiciales y apremiantes objetivos públicos. Y, añade el jurista nortemericano, “[u]n estudio más completo de la práctica legal incluiría a [la actividad de] legisladores, policías, abogados de distrito, funcionarios de bienestar social, presidentes de consejos escolares, una gran variedad de otros funcionarios y personas como banqueros, empresarios y trabajadores sindicalistas, que no reciben el nombre de funcionarios públicos pero cuyas decisiones también afectan los derechos legales de sus conciudadanos" 33 .

A partir de la síntesis de estos elementos pueden en teoría argumentarse una serie de soluciones. Pero solo una de ellas puede indicar plenamente lo que tiene que reconocerse como el Derecho efectivamente vigente en un determinado conjunto político y en un determinado período histórico. En El imperio de la justicia, que también incluye una larga confrontación con las teorías hermenéuticas de Hans-Georg Gadamer, se afirma que el Derecho tiene una esencia interpretativa. Por lo tanto, cobra vida en las sistematizaciones narrativas que los jueces construyen a partir de todo el material que pueden (y deben) tomar en consideración. Si estas narraciones, como ya hemos dicho, no pueden de ninguna manera aspirar a alcanzar una verdad de tipo lógico-racional, no se transforman por eso en cuentos sin ningún valor o solamente provistos de un valor estético.

En un célebre ensayo titulado precisamente ¿Realmente no hay respuesta correcta en los casos difíciles? ${ }^{34}$, Dworkin nos proporciona un ejemplo esclarecedor. La búsqueda de la única solución correcta, él afirma, se parece

33 R. DWORKIN, El imperio de la justicia, cit., p. 22.

34 Vid. R. DWORKIN, "No Right Answer?”, New York University Law Review, LIII, núm. 1, 1978, pp. 1-32; en castellano, “ ¿Realmente no hay respuesta correcta en los casos difíciles?”, 
a un hipotético juego literario sobre la novela David Copperfield de Charles Dickens. Se trata de un juego en que los participantes se ponen una serie de preguntas sobre el protagonista, a las cuales el autor no dio en el libro una respuesta clara. Esto porque para la estructura de la novela no retuvo necesario proporcionarles a ellas una respuesta; porque retuvo conveniente mantener un halo de misterio alrededor de ellas; para que los lectores se interogaran autónomamente; o por qualquier otra razón. Es verdad que hay preguntas a las que no se puede dar una respuesta correcta, porque el libro carece de todo serio punto de apoyo argumentativo (por ejemplo, ¿qué tipo de sangre tiene David?). Pero hay también muchísimas preguntas (por ejemplo ¿David quiere verdaderamente a su madre?) que permiten la construcción de narraciones en competencia unas con otras, a partir de los acontecimientos expuestos en la novela. Y entre ellas puede elegirse la que parece tener el mayor número de argumentos en su favor ${ }^{35}$.

Alguien podría ahora afirmar que Dworkin acaba dando la razón a aquellos positivistas que creen que en el Derecho hay casos que no pueden resolverse, como el relativo al tipo de sangre de David. Cuando ellos se encuentren, obligarían a los jueces a utilizar su plena discrecionalidad. Pero cabe notar que, si las informaciones que pueden extraerse de una novela o de la biografía de su autor son siempre relativamente reducidas, es al contrario raro que el material jurídico existente no proporcione ningún comienzo de una cadena argumentativa. Sin duda, "[1]a proposición según la cual cuando no se dispone de una norma clara se ha de ejercer la discreción, en el sentido de "juicio", es una tautología" 36; pero, si bien "[e]s posible que el derecho no sea un sistema sin lagunas", se le puede sin embargo pedir a un juez conscienzudo que "lo trate como si lo fuera" ${ }^{37}$.

en P. CASANOVAS/J.J. MORESO (comps.), El ámbito de lo jurídico, Crítica, Barcelona, 1994, pp. 475-512.

35 Sin embargo, objeta Riccardo GUASTINI en la introducción a su traducción italiana del ensayo de Dworkin ("Soluzioni dubbie. Lacune e interpretazione secondo Dworkin. Con un'appendice bibliografica", Materiali per una storia della cultura giuridica, XIII, núm. 2, 1983, p. 454), la nueva versión de David Copperfield sería apócrifa, tal y como lo sería un sistema jurídico retrazado por unos jueces que recurran a principios no expresamente establecidos. Sobre las diferencias entre interpretación jurídica y literaria, véase S. SHPALL, “Dworkin's Literary Analogy", en D. PLUNKETT/S.J. SHAPIRO/K. TOH (eds.), Dimensions of Normativity: New Essays on Metaethics and Jurisprudence, Oxford University Press, Oxford, 2019, pp. 365-392.

$36 \quad$ R. DWORKIN, Los derechos en serio, cit., p. 87.

37 Ivi, p. 190. DWORKIN argumenta la cuestión en la manera siguiente: "[S]upongamos [...] que el sistema jurídico [...] esté muy avanzado y que rebose de reglas y prácticas 
Por lo tanto, podemos preguntarnos: ¿Dworkin piensa realmente que es posible encontrar para cada caso jurídico una respuesta correcta, es decir tan adecuada que todas las demás deben considerarse erróneas?

Quizás es posible sostener una lectura semejante con respecto a Justicia para erizos, aunque la fórmula de la "única respuesta correcta" se haga en Dworkin con el tiempo cada vez más rara. Sin duda se rechaza aquí el objetivismo ético de los que pensaran que existen partículas morales, que Dworkin llama irónicamente los "morones". Él intenta asimismo "tomar en serio" la ley de Hume, según la cual no se puede sin mediación pasar de afirmaciones descriptivas a afirmaciones prescriptivas; lo cual significa que todos los razonamientos morales se mueven en un círculo lógico, porque no pueden más que partir de juicios igualmente morales. Pero esto no implica para Dworkin afirmar, como hace la mayoría de los intérpretes de la ley, que en los asuntos morales la verdad no existe, sino solamente que ella no puede tener un fundamento externo a la misma moral, aunque no pierda su estatuto de verdad. Hay, según Dworkin, valores que no pueden sino imponerse a la experiencia jurídica y política, y entonces sería relativamente fácil para los jueces conscienzudos inspirarse en ellos al pronunciar sus sentencias.

Por supuesto, esto no quita que siga existiendo el problema ya subrayado del fundamento sobre todo emocional de estos valores ${ }^{38}$.

constitucionales, de precedentes y de estatutos. La probabilidad antecedente de un empate [...] bien podría ser tan baja como para justificar una nueva regla fundamental de la empresa que prescriba a los jueces la eliminación de los empates de la gama de respuestas que podría ofrecer. Una instrucción tal no niega la posibilidad teórica de un empate, sino que supone que, dada la complejidad de los materiales jurídicos con que se cuenta, si lo meditan con calma y con tiempo, los jueces llegarán a pensar que, todo sopesado, una u otra de las partes tiene el mejor conjunto de razones alegadas. Esta nueva instrucción será racional si la probabilidad antecedente de error en una decisión judicial parece mayor que la probabilidad antecedente de que algún caso sea, de hecho, un empate, y si hay ventajas de finalidad u otras ventajas políticas que se puedan obtener negando la posibilidad de casos de empate en el derecho. Naturalmente, la instrucción no será racional, sino absurda, si el sistema jurídico no ofrece la complejidad suficiente para justificar semejante cálculo de las posibilidades antecedentes" (ivi, p. 406).

38 Justicia para erizos, que no se ocupa principalmente de Derecho, contiene en general partes muy interesantes, como la crítica al escepticismo moral o la discusión sobre el problema del libre albedrío. Pero hablar de esos asuntos tendría sentido, en nuestro trabajo, solo si no hubiesemos ya declarado menos concluyente el esfuerzo de Dworkin de proporcionar un fundamento a los valores. Este fracaso se repercute al contrario también en la (no clarísima) doctrina expresada en el capítulo XIX (cit., pp. 485-505), en que Dworkin indica una aún más estricta convergencia de Derecho y moral como objetivo de su definitiva doctrina

ISSN: 1133-0937

DOI: https://doi.org/10.20318/dyl.2021.5852
DERECHOS Y LIBERTADES

Número 44, Época II, enero 2021, pp. 137-166 
Diferente es el discurso desarrollado en las obras de los años 70 y 80, en que Dworkin se enfrenta a dos problemas. El primero se refiere a la posibilidad que un juez de carne y hueso pueda realmente encontrar todo el material jurídico existente para cada uno de los casos de que se ocupa, y pueda realizar una construcción argumentativa para encontrar su única justificación posible. Como dice el propio Dworkin, "[s]i nos limitamos a designar nuestra regla de reconocimiento con la frase "el conjunto completo de principios en vigor", a lo único que llegamos es a la tautología según de que el derecho es el derecho. $\mathrm{Si}$, en cambio, intentáramos efectivamente enumerar todos los principios en vigor, fracasaríamos. Los principios son discutibles, su peso es importante, son innumerables, y varían y cambian con tal rapidez que el comienzo de nuestra lista estaría anticuado antes de que hubiésemos llegado a mitad" ${ }^{39}$. No es causalidad que Dworkin llame Hércules al único juez capaz de cumplir un trabajo similar, porque los jueces normales son como mucho capaces de averiguar plena y escrupulosamente solo vertientes reducidas de los casos que se les someten ${ }^{40}$.

En cambio, el segundo problema, mucho más fundamental, se conecta con la exclusión de todo procedimiento lógico de decisión en el Derecho. Si se rechaza, en efecto, un criterio común, como el de razón, para distinguir entre alegaciones jurídicas verdaderas y falsas, debería encontrarse un criterio alternativo; pero Dworkin no lo indica de manera adecuada. Él mismo reconoce que deben excluirse los criterios estrictamente matemáticos, como el conteo del número de precedentes que las diferentes soluciones alternativas respetan o rechazan. Estos criterios no son satisfactorios, también porque es imposible encontrar su fundamento. Los criterios alegados tienen que ser cualitativos, es decir tienen que referirse al peso de los principios, y no cuantitativos, lo que significaría mecánicos. Y, sin embargo, la calidad sufre del relativismo interpretativo que aquí se intenta superar.

jurídica (una crítica de estas páginas se halla en L.G. SAGER, "Putting Law in Its Place", en W. WALUCHOW/S. SCIARAFFA [eds.], The Legacy of Ronald Dworkin, Oxford University Press, Oxford, 2016, pp. 117-129; véase también A. POLICAR, “La connaisance morale selon Ronald Dworkin. Le réalisme en question”, Raison publique, XX, núm. 1, 2016, pp. 257-269).

39 R. DWORKIN, Los derechos en serio, cit., p. 99.

40 Correctamente nota Robert ALEXY que, en sentido estricto, "una única respuesta correcta para cada caso sólo podría admitirse recurriendo a cinco idealizaciones, a saber: 1) tiempo ilimitado, 2) información ilimitada, 3) claridad lingüística conceptual ilimitada, 4) capacidad y disposición ilimitada para el cambio de roles y 5) carencia de prejuicios ilimitatada" ("Sistemas jurídicos, principios jurídicos y razón práctica", Doxa. Cuadernos de Filosofía del Derecho, núm. 5, 1988, p. 151). 
Entonces, puesto que el propio Dworkin parece consciente de los limites de su teoría, podemos ahora preguntarnos qué lugar tiene la doctrina de la única respuesta correcta en la construcción filosófica del jurista norteamericano; y también si pueden justificarse las críticas que ella deja surgir.

Para el valor abstracto de la teoría no parece tan importante saber dónde se esconde el juez Hércules. En cambio la falta de un criterio común para evaluar su trabajo y para reconocer su incuestionable superioridad profesional relega esta doctrina a poco más que a un cumplimiento retórico de la interpretación argumentativa del Derecho. Y se puede también ser indulgentes con Dworkin por utilizar el recurso dialéctico de enunciarla con términos de sentido absoluto, escondiendo su ineludible fondo de relatividad ${ }^{41}$. La única solución correcta podría declinarse, en su caso, o como la más convincente para los jueces más conscienzudos y meticulosos, o como la capaz de eludir la mayor cantidad de objeciones, o como la capaz hasta ahora de debilitar todas las demás (según un procedimiento popperiano de falsificación), o lo que sea ${ }^{42}$.

Dicho esto, hay también otra posible interpretación, que sin embargo es interesante poner de relieve. Llamar Hércules al único juez capaz del inventario del material para la resolución adecuada de los casos jurídicos implica transformar esta resolución en una idea regulativa de tipo kantiano. Esto significaría postular, más allá de toda posibilidad de realización empírica, la existencia de una esencia objetiva del Derecho como horizonte unitario, síntesis y posible justificación de todos los hechos jurídicos. Para el Kant de la Crítica de la razón pura, y precisamente de la parte denominada Dialéctica

41 Comprender esto significa, en nuestra opinión, no poder dar la razón a GUASTINI, cuando afirma que "Dworkin participa sin reconocerlo en el viejo y agotado dogma de la coherencia del Derecho" (Soluzioni dubbie, cit., p. 455).

42 Aunque criticando a Dworkin, ofrece una lectura análoga el académico finlandés Aulis AARNIO en su artículo en castellano "La tesis de la única respuesta correcta y el principio regulativo del razonamiento jurídico", Doxa. Cuadernos de Filosofía del Derecho, núm. 8, 1990, pp. 23-39. De todas maneras, pone de relieve SCHIAVELLO, en Diritto come integrità, cit., pp. 228-244, ya en El imperio de la justicia Dworkin abandona la one right answer thesis como dispositivo de enfrentamiento radical con el positivismo y su teoría de la discreción judicial en favor de una visión más moderada. Además, no se puede negar que de vez en cuando Dworkin acaba por trivializar excesivamente su teoría; por ejemplo, en su refutación de la crítica de Richard Rorty, al decir que la prueba de la exactitud de la doctrina de la única respuesta correcta se halla en el hecho de que mucha gente piensa tener la solución mejor a algunos casos jurídicos (cfr. R. DWORKIN, La justicia con toga, cit., pp. 52-53). Como nosotros, Rorty acusa a Dworkin de ser un metafísico según el cual existe "allá afuera (out there)" un mundo objetivo de valores; y a Dworkin non se le ocurre nada mejor que diluir así su teoría. 
transcendental, esto sería también un llamamiento moral a la razón teórica para que salga de sus límites y se abra a la experiencia práctica ${ }^{43}$.

Sin duda, una interpretación similar parece particularmente adecuada para el Dworkin que "coquetea" con el Derecho natural a través del principio de igualdad de respeto y consideración. Como este, también los principios kantianos, por constitución y estructura, solo pueden ser universales y expresan un criterio exclusivamente formal y procedimental ${ }^{44}$. Y, en este sentido, el horizonte transcendental, hacia el que se orienta toda la experiencia jurídica, quizá pueda describirse, en los términos de Rudolf Stammler, uno de los neokantianos de Marburgo, como el del Derecho justo (richtiges Recht).

No obstante, una interpretación semejante ni siquiera está fuera de lugar en una concepción que, como la nuestra, intenta poner de relieve las vertientes positivistas y realistas, sobre todo en el sentido de empíricas, de la obra de Dworkin.

43 En este sentido, no consideramos del todo exacta la aclaración de ALEXY, según el cual «[1]a idea regulativa de la única respuesta correcta no presupone que exista para cada caso una única respuesta correcta. Sólo presupone que en algunos casos se puede dar una única respuesta correcta y que no se sabe en qué casos es así, de manera que vale la pena procurar encontrar en cada caso la única respuesta correcta» ("Sistemas jurídicos, principios jurídicos y razón práctica", cit. p. 151). Por el contrario, en nuestra opinión, la doctrina de la única respuesta correcta presupone que se puede declarar su inexistencia solamente en los casos en que ni siquiera hay elementos jurídicos básicos para analizar y para extraerla. En los demás casos ella existe, aunque jamás nadie la encuentre; porque encontrarla "allá afuera" es estructuralmente impossible, mejor inconcebible, como lo sería encontrar las ideas kantianas de la razón. Julie ALLARD, en "Dworkin est-il kantien?", en A. POLICAR (ed.), Ronald Dworkin, l'empire des valeurs, Classiques Garnier, Paris, 2017, pp. 191-206, entiende esta vertiente en manera semejante. No obstante, prefiere explicar la similitud entre Dworkin y Kant refiriéndose a los juicios reflectantes, estéticos y teleológicos, del que se habla en la Crítica de la facultad de juzgar. Como en el juicio estético, en Dworkin, «no es el contenido de los principios que al juez le serviría, sino la referencia a los principios, el ponerse a su nivel, que le permitiría decidir entre diversas interpretaciones de la misma regla jurídica. Esto es kantiano, porque en Kant universal es el principio de la facultad de juzgar, no su contenido. Lo importante es que reconozcáis mi pretensión a la universalidad, no la verdadera universalidad de mi juicio» (ivi, p. 205). En cambio, añade la autora, otras características acercan la doctrina de Dworkin al concepto de juicio teleológico: «el objetivo de coherencia que Dworkin atribuye a los juicios, la pretensión del juez de pensar en el Derecho como en un todo, obra de un único autor, y de incluir en él su decisión». El juez «está obligado a hacer como si el Derecho fuera un sistema, como si el Derecho fuera justo, como si él fuera Hercules, etc.» (ivi, p. 206 n).

44 Como se ha dicho supra, nota 20, citando las palabras de Dworkin, la consecución de la igualdad de respeto y consideración no aparece como algo actual, sino como "caso límite". Y el objetivismo moral de Justicia para erizos está también imbuido de semejantes significados aspiracionales.

DERECHOS Y LIBERTADES

ISSN: 1133-0937

Número 44, Época II, enero 2021, pp. 137-166

DOI: https://doi.org/10.20318/dyl.2021.5852 
En efecto, empírica es una doctrina interpretativa del Derecho en la medida en que implica que los asuntos jurídicos pueden discutirse solamente desde el punto de vista de los que participan en ellos; entonces, no desde el punto de vista externo y neutral de los sociólogos o de los antropólogos, y tampoco de los filósofos. Supongamos, Dworkin afirma, que podemos persuadir a un filósofo para estudiar Derecho y convertirse en juez. Luego le encargamos de la decisión de algunos casos concretos. Pues bien, él podría afirmar "que aunque tiene esas creencias, las tiene solamente porque ha recibido una formación jurídica y se ha incorporado por consiguiente a un grupo cuyos miembros, en virtud de dicha formación, participan en un mismo mito". Él podría asimismo negar "que un observador independiente, que no fuera a su vez participante en el grupo, pudiera decidir, por lo menos en los casos controvertibles, que las teorías y juicios de uno de los participantes fueran superiores a las de otro. Pero, ¿a qué alude aquí la idea de un observador independiente? Si alude a alguien que no ha tenido formación jurídica, no es sorprendente, pero tampoco viene al caso, que un observador tal sea incompetente para formarse opiniones sobre lo que hacen los participantes" ${ }^{45}$.

Entonces, una doctrina interpretativa del Derecho significa para Dworkin una investigación sobre las argumentaciones que sus protagonistas, sea cual sea su papel en la sociedad, desarrollan en el momento en que actúan jurídicamente. Sin duda Dworkin rechaza un análisis del Derecho en los términos de la lógica tradicional, y ni siquiera se interesa de cuestiones de lógica deóntica. Pero su teoría no parece excluir la existencia de una lógica peculiar del Derecho, o mejor la existencia de tantas lógicas argumentativas cuantas son las situaciones jurídicas que pueden analizarse. Si el Derecho empírico no es más que un conjunto fragmentario de hechos de diferente naturaleza, el horizonte regulativo de la única respuesta correcta puede constituir para cada ordenamiento solo una esperanza inmanente: la de encontrar sistemas argumentativos siempre más sofisticados, o tal vez nuevos lenguajes jurídicos, para alcanzar una siempre mayor unidad y para hacer las sentencias de los tribunales siempre más previsibles y consistentes. Lo cual tal vez implicaría una nueva lectura de Dworkin, que aquí no se puede obviamente desarrollar, a la luz de las teorías de la argumentación del último siglo.

También en este caso, no es todo lo que Dworkin quería encontrar, pero pudiera todavía ser mucho.

45 R. DWORKIN, Los derechos en serio, cit., pp. 402-403.

ISSN: 1133-0937

DOI: https://doi.org/10.20318/dyl.2021.5852
DERECHOS Y LIBERTADES

Número 44, Época II, enero 2021, pp. 137-166 


\section{EL DERECHO INJUSTO}

Sin embargo, una cuestión delicada, que ya hemos en parte analizado, vuelve aquí a presentarse. Es la de la posición que Dworkin toma a propósito del Derecho injusto o incluso criminal, como por ejemplo el nacionalsocialista o el de del régimen de apartheid en Sudáfrica. La pregunta no puede más que tener este tenor: ¿existen principios nazis o principios del régimen de apartheid? Y en la doctrina de Dworkin esto significa: si un ordenamiento se inspira explícitamente a estos principios, quizás en una constitución escrita, ¿sus jueces podrían encontrar la única respuesta correcta solo respetándolos y aplicándolos? Dicho aún más claramente: ¿es posible que en semejantes ordenamientos en la mayoría de los casos la búsqueda de la única respuesta correcta pueda solo producir sentencias que discriminan a los judíos o a los negros en favor de los arios o de los blancos? ${ }^{46}$

También en este caso, la solución depende de la interpretación del Derecho de la que se parta. Si se parte de una perspectiva realista en sentido amplio, la solución no puede que ser positiva; mientras que si se piensa que el Derecho tiene necesariamente que inspirarse en el principio de igual respeto y consideración para todos los individuos, dentro y fuera del ordenamiento, la solución no puede más que ser negativa. La segunda, como ya hemos dicho, es la posición que Dworkin toma en los ensayos de política del Derecho contenidos en Los derechos en serio. En este libro la distinción entre principios y políticas, que suena ya bastante instrumental y que nunca el autor aclara suficientemente, acaba por comprimirse entre aquella otra constituida por los derechos individuales y los fines de la comunidad; como si no fuera posible la existencia también de principios de valor comunitario.

Para discutir esta posición, es suficiente, por ejemplo, imaginar un ordenamiento en que las leyes escritas, quizás también las constitucionales, y la mayoría de los precedentes judiciales muestren unidad determinando una particular ideología de Estado. Esta ideología podría estar inspirada en valores weberianamente "irracionales" como la gloria nacional o la superioridad racial, o bien a valores más "racionales" como la fuerza militar o la eficiencia económica. Asimismo se puede imaginar un sistema formado por una cons-

${ }^{46}$ Como nos recuerda David DYZENHAUS en "Dworkin and Unjust Law", en W. WALUCHOW/S. SCIARAFFA (eds.), The Legacy of Ronald Dworkin, cit., p. 133, este es el razonamiento que hizo el jurista sudafricano y seguidor del interpretativismo dworkiniano Raymond Wacks, cuando alentó a los jueces liberales de su país para que dimitieran en lugar de resignarse a su única otra posibilidad: aplicar un Derecho injusto.

DERECHOS Y LIBERTADES

ISSN: 1133-0937

Número 44, Época II, enero 2021, pp. 137-166

DOI: https://doi.org/10.20318/dyl.2021.5852 
titución, leyes ordinarias y precedentes que no sea unívoco al determinar los valores nacionales, pero que se inscriba en una sociedad, y por lo tanto también en un conjunto de jueces y tribunales, que se reconocen en una ética social racista o economicista. Y es interesante notar que el primer caso parece ser el de los Estados Unidos en algunos períodos de su historia. De todas maneras, no se comprende teóricamente por qué en estos casos la consecución de la supremacía de los blancos frente a los negros, o bien, para detenerse al ejemplo del propio Dworkin, el reconocimiento en una sociedad capitalista del hecho de que la vida de un banquero vale más de la de un obrero, tengan que llamarse como mucho políticas, mientras el respeto de la vida y de la igualdad de cada cual puedan ambir al nombre más halagador de principios.

Dworkin, refiriéndose precisamente a la experiencia del nacionalsocialismo y del régimen de apartheid, afirma que "hay casos reales en que el derecho institucional [...] entra claramente en conflicto con los derechos morales básicos" ${ }^{47}$; y, como haría qualquier partidario del Derecho natural, sostiene que los segundos entran en el cálculo de los derechos jurídicos que las personas pueden asumir, cuando los materiales jurídicos ordinarios ofrezcan una conducción insegura. Además, unas líneas después él añade que "el derecho institucional proporciona una razón auténtica -cuya importancia variará con la justicia o la injusticia general del sistema en su totalidad- para decidir de una manera, pero hay ciertas consideraciones morales que constituyen una razón importante en su contra" ${ }^{48}$. Basándose en esto, se niega la distinción positivista entre Derecho y moral, y se intenta argumentar platónicamente la conveniencia de una noble mentira por parte de los jueces para esconder el conflicto ${ }^{49}$.

Pero, en nuestra opinión, más que enredarse en explicaciones problemáticas, resultaría más lineal perseverar en la individuación de una lógica peculiar

$47 \quad$ R. DWORKIN, Los derechos en serio, cit., pp. 450-451.

48 Ivi, p. 451. Estas palabras, cabe notar, se hallan en la parte de la Réplica a los críticos dedicada a las tesis de Greenawalt.

49 Cfr. ivi, p. 468. Pese a esto, cabe señalar, que en la página siguiente DWORKIN ya vuelve a aumentar la confusión, afirmando ex abrupto que "el hecho de que los principios jurídicos deban ser principios morales [...] podría, en ciertas circunstancias, excluir los argumentos que defienden los supuestos principios en sistemas jurídicos perversos. Pero no debo confiar demasiado en el poder de attracción del concepto de principio moral. No hay ningún análisis convincente de ese concepto que asegure que el principio de que los negros son menos dignos de consideración que los blancos pueda ser rechazado considerando que no es en modo alguno un principio" (ivi, p. 469). Desagradablemente, ya lo hemos dicho, nunca se puede esperar en las páginas de Dworkin de leer siquiera un intento de resolución de estas contradicciones. 
del Derecho. En este sentido, junto a Hart en su oposición al presunto Derecho supralegal del que habla el último Radbruch, se puede reconocer explícitamente la esencia necesariamente no jurídica de una legítima desobediencia al Derecho injusto. Nadie, menos aún desde una perspectiva realista, afirma que el Derecho tiene siempre que ser respetado; más bien, como es sabido, esto implicaría asumir la perspectiva que Norberto Bobbio llamó " positivismo ideológico" y que se puede explicar como una forma particular de Derecho natural ${ }^{50}$.

En el Imperio de la justicia la cuestión, en cambio, se aborda desde otro punto de vista y con una actitud aparentemente más realista. La pregunta sobre si la Alemania nazi tenía un Derecho, afirma ahora Dworkin, debe responderse afirmativamente si no queremos determinar en detalle lo que es el Derecho -es decir, si huimos de lo que él denomina "aguijón semántico (semantic sting)" - y, como en el caso de las reglas del juego, nos referimos a los principios generalísimos que estructuraron cada experiencia jurídica en la historia. Desde un punto de vista interpretativo, por el contrario, la respuesta depende del concepto de Derecho que los intérpretes adopten en sus estipulaciones, aunque a menudo con una actitud crítica. Dworkin supone también la existencia de un juez de un ordinamiento con características criminales, que llama con el nombre alemán de Sigfrido. Con respecto a él, afirma Dworkin, podríamos eludir la cuestión ética, preguntándonos cómo posiblemente actuará, en vez de preguntarnos cómo debiera actuar. Así nos interrogaríamos también en su caso sobre los principios que él tiene que utilizar y sobre cómo podría alcanzar su única respuesta correcta. Pero no puede pasar aquí inadvertido, aunque Dworkin no lo diga expresamente, que Sigfrido parece ser de cabo a rabo igual que Hércules.

Sin embargo, a esta interpretación prometedora no se da curso. También en estos breves comentarios, si bien con énfasis menor, el autor vuelve enseguida a la cuestión del ineludible contenido ético del Derecho.

\section{CONCLUSIONES}

En todo caso, queremos llegar a la conclusión analizando el problema del Derecho injusto en relación con las críticas anteriormente contrapuestas a la teoría de Dworkin.

50 Cfr. N. BOBBIO, “Aspetti del positivismo giuridico", en Giusnaturalismo e positivismo giuridico, Edizioni di Comunità, Milano, 1965, pp. 110-112. 
En primer lugar, cabe señalar que Dworkin una vez más no deja de incrementar la confusión sobre los límites de aplicación histórica de sus estructuras especulativas. Para reducir, como dice, la emoción generalmente relacionada a los discursos sobre el nacionalsocialismo o el apartheid, él propone que se consideren cuestiones lejanas en el pasado, como la de un juez romano que tuviese que decidir un caso de esclavitud. En una obra que, a diferencia de las precedentes, quiere ser más sistemática, sería menester con mayor razón aclarar los fundamentos teóricos de los que el autor tenía intención de partir. Pero Dworkin, como en otros lugares, le deja al intérprete las dificultades de este papel.

En segundo lugar, vuelve a presentarse en otra perspectiva la cuestión de la esencia descriptiva o prescriptiva de las posiciones de Dworkin. Hemos dicho anteriormente que una posición media en la alternativa tendría el efecto positivo de balancear la conciencia de lo que los jueces hacen más frecuentemente de lo que se cree con el reconocimiento de la conveniencia de que lo hagan. De esta manera el Derecho gozaría como mínimo de mayor estabilidad empírica. Pero, frente al Derecho injusto, solo la primera parte en determinadas condiciones puede ser verdadera, mientras la segunda se vuelve infinitamente más problematica. Por supuesto, tampoco en una perspectiva realista, tendría sentido cambiar una mayor coherencia en el examen de la realidad jurídica por la vigencia de un sistema que, al menos en determinadas latitudes, está en conflicto con las opiniones éticas más profundas de la mayoría de los expertos de Derecho.

Resumamos por fin todo el trayecto de nuestra discusión.

El asunto del Derecho injusto acaba por subrayar de manera aún más esclarecedora la aporía fundamental que afecta la obra de Dworkin. Como ya hemos visto, si la interpretamos desde el punto de vista del Derecho natural, ella presenta problemas tanto por el lado de la coherencia como por el de la complejidad. En cambio, si, como hemos intentado hacer, la leemos como un positivismo sui generis, esta doctrina tiene el mérito de considerar con mayor atención la vertiente material y contingente de la experiencia jurídica. Pero a este mérito no le corresponde siempre una reconstrucción de la actuación efectiva de los jueces (de la cual, en realidad, tampoco se interesa el Derecho natural) ni siquiera de la manera en que sería bueno que actuasen.

No obstante, seguimos juzgando más prometedora esta segunda interpretación. Ella nos aparece fundamental para describir el tenor de los llamamientos que los juristas a menudo dirigen a los jueces para que den a 
sus sentencias un sentido más cercano a la complejidad de las experiencias jurídicas particulares. Por supuesto, no se nos escapa que eso puede ocurrir constantemente solo cuando los expertos en Derecho no tengan motivos de repulsión bastante poderosos con respecto a lo que creen ser el Derecho vigente. En cuyo caso, se repite, más allá de ese reconocimiento de la realidad jurídica puede haber solamente un llamamiento no jurídico, en tanto que inspirado en valores no jurídicos, a pasar por alto el Derecho vigente.

De esta manera, llegamos asimismo a subrayar la evidente proximidad de estas doctrinas, al menos por como hemos intentado interpretarlas, con muchos rasgos fundamentales del postivismo de Hart. Èl mismo Hart, por otra parte, se dio cuenta de eso en el Post scríptum a El concepto de derecho. Pero creemos que Dworkin, por las motivaciones que hemos intentado aclarar, podría justificadamente reivindicar frente al filósofo inglés una visión más compleja del sentido material y empírico del Derecho.

Sin duda, esto no es todo, y alguien podría legítimamente sostener que ni siquiera es mucho. Sin embargo, quizás se puede también afirmar, conforme a nuestro intento, que esta reconstrucción ha sido como mínimo capaz de preservar la fecundidad y la originalidad de algunas partes de la doctrina de Dworkin.

GIORGIO RidOLFI

Università di Pisa

Dipartimento di Giurisprudenza

Piazza dei Cavalieri 2, 56126, Pisa

e-mail: giorgio.ridolfi@unipi.it 